\title{
Business Process Management and Outsourcing
}

\author{
Jamila Niazi, Shantanu Prasad
}

\begin{abstract}
This paper investigates to appoint the fundamental information about outsourcing implications and emphasizes the essential gains and drawbacks of this paper. The objective of the work is to picture the impact of outsourcing on organizational performance and profitability through risk management and alyzing, comprehending the factors, which influence the process of outsourcing. Studying the efficiency of organizational performance and analyzing the attitude of companies for their improvement using outsourcing is another objective of this research. The aim of outsourcing in corporatel industry is to evaluate the improvement in the performance of the organizations that was mentioned by researchers in literature. Researchers had analyzed the outsourcing and its implication as an important strategy of company many years ago. The outcome is established to demonstrate outsourcing framework from different prospective. Performance effects are inquired by level of operating profit, acquiring margin return on shareholders' capital and diminution in employment cost can be the significance of outsourcing, which have been followed by organizations. The liquidity of companies that increase by passage of time is the indication of profit. Moreover, managing the risk is the essential aspect for earning profitability of the project.
\end{abstract}

Keywords: Outsourcing, core competency, business process.

\section{INTRODUCTION}

\subsection{Background of Study:}

The word outsourcing is made up of two terms "out" and "sourcing". Sourcing indicates the act of handing over the activities, responsibilities and decision-making process to some other company or firm. "Out" means external/other organization.

When a company transfers its one or more part of its responsibilities for performing or managing the business process to another company; is called as business process outsourcing. Usually, the companies tend to outsource challenging and knowledgeable parts of their activities i.e. software development and infrastructure management like HR and payroll (Dayasindhu, (2004).

Generally, companies have many choices for outsourcing purpose such as: Onshore (within their own country, Near Shore (Neighbor countries), the last but not the least Offshore (distant countries).

The outsourcing terminology has been driven from American Glossary 'Outside-Resourcing' which means transferring of activities and responsibilities from one

\footnotetext{
Revised Manuscript Received on September 10, 2019.

Jamila Niazi, MBA Student, SCMHRD, Symbiosis International (Deemed University), Pune, Maharashtra, India.

(Email: Jamila_niazi@scmhrd.edu)

Shantanu Prasad, Assistant Professor, SCMHRD, Symbiosis International (Deemed University), Pune, Maharashtra, India.

(Email: shantanu_prasad@scmhrd.edu)
}

business entity to another business organization. As the days goes on, the outsourcing process speeds up its growth accordingly, as in the last two decades outsourcing has played a vital role in business.

In order to get the right result, it is very important for the organization to select the right sourcing and the company must know clearly that which activity must be outsourced and how to priorities those activities which are entitled for outsourcing. Generally, Chunkification Strategy is being used by the companies, in which they divide the process/activities into different parts or chunk for effective outsourcing and reducing the risk there off. (Nicholson Brain, Aman Aini. (2008). Offshore Accounting Outsourcing)

Low price outsourcing does not mean the right outsourcing, the right outsourcing means to receive the best return. Therefore, proper outsourcing is like proper strategic planning and proper investment. (Ravi and Sashi, 2005).

According to (Gulzhana, 2012)-Advantages and disadvantages outsourcing: analysis of outsourcing practices of Kazakhstan banks), the business process organizations should first of all find an outsourcing partner, then negotiate and sign the contract with, then confirm the delivery capacity and at the end focus on how to govern the relationship in a good manner which leads to achieve the required needs.

The outsourcing process is a two side/two way relationship and each side has a vital role to play in order to achieve the maximum satisfaction level, hence this paper is being prepared to support the both partners to address the risk available, and choose the right partner. When a company does not know about the performance of the partner's company, it is a big risk for the company to invest its money and time on a new business and obviously when they handover their responsibilities to the outsourcing company, they automatically lose their control over the transferred activities. It is expected that the outsourcing company may not perform well and ignore the quality. By choosing the right governance method, both the parties can manage the risk in a better way, create new source of value and spot fluctuations to accept the changes in business (Chandrasekaran, et al., 2007).

To match their culture, expectation and target, the right governance may help them and also the right governance may support them in aligning the company's goals and outsourcing, choosing the right model of outsourcing to 
manage the business process in a better way may help the company to grow faster and increase their revenue and market share.

The organization that is searching for an outsourcing company, before selecting it, the company should search about the related experience of the company and ask them for reference, and then the company should ask the related questions from the previous customers or dealers. The company should make sure that the outsourcing company is financially stable, as finance is the most critical part to take care of. Organization may review the sample work of the outsourcing company and to carry out the final decision and to make sure that the considered organization is having the right equipment or not, organization may check both their infrastructure as well as technology. This is an International reputed journal that published research articles globally. All accepted papers should be formatted as per Journal Template. Be sure that Each author profile (min 100 word) along with photo should be included in the final paper/camera ready submission. It is be sure that contents of the paper are fine and satisfactory. Author (s) can make rectification in the final paper but after the final submission to the journal, rectification is not possible. In the formatted paper, volume no/ issue no will be in the right top corner of the paper. In the case of failure, the papers will be declined from the database of journal and publishing house. It is noted that: 1. Each author profile along with photo (min 100 word) has been included in the final paper. 2. Final paper is prepared as per journal the template. 3. Contents of the paper are fine and satisfactory. Author (s) can make rectification in the final paper but after the final submission to the journal, rectification is not possible.

\subsection{Problem Statement:}

Undoubtedly, outsourcing seems very risky for complex business process. When the outsourcing activity is not core activity, it is easy to address the risk, but if the activity is core activity then finding out the risk becomes a complicated task. Nowadays, though the Globalization and advanced Technology helps the organizations to perform their tasks very easily in comparison to the past, but still there are many companies, which get disgraceful outcomes or sometime failure, which make them to revise or cancel the contract with their partners. Outsourcing failure happens due to lack of perfect strategy. Existence of misunderstanding between the outsourcing aims and strategy of the partner may lead to dissatisfactions and less focusing on the core activities.

\subsection{Objectives of the Study}

- To relate how outsourcing impact on organization profitability.

- To analyze the in depth use of outsourcing in corporate to improve performance.

- To study the efficiency of organizational performance.

- To comprehend the factors which influence the process of outsourcing.

- To analyze the attitude of companies for their improvement using outsourcing.

\subsection{Aim of the Study:}

In modern era, by improving of organizational performance using of outsourcing enable companies be stable among competitors by providing better quality services. Outsourcing is the way of managing and performing the organizational performance in better way and lower cost by partnership with specialized services providers. For improvement of its process, it can leverage on the capabilities and expertise. Because the service provider delivers, good services to customers in better way, which attract more customers and provide much higher efficiency and profitability. While providing efficient services cause customers satisfaction. The result in organization would linked with earning enormous benefit.

\subsection{Significance of the Study:}

The current research bundle of questions contains "How outsourcing strategy impact on the organizational performance?" and "How outsourcing effect on organizational profitability?" According the research questions, this study focuses on outsourcing strategy in organizational performance and profitability through risk management while implementing outsourcing process.

The required responses will be examined through literature review, whether the null hypothesis should be accepted or rejected.

\subsection{Scheme of the Study}

- Introduction of the study, problems statement, Aim of study, research objectives, and significance of the Study.

- Literature review.

- Research method

- Analysis and results

- Conclusion and Recommendation.

\section{LITERATURE REVIEW}

\subsection{Review of Literature:}

Outsourcing strategy indicates that sort of outsourcing which aligned with the long-term goals of the company. Achieving competitive advantage, freeing up the resources for core/main activities, repositioning of the market and market share are some of the benefits that the company is expecting out of outsourcing strategy (Henderson \& Venkatraman, 1999)

Outsourcing strategy causes improvement in overall organizational performance through reducing the cost and risk factors, enhances flexibility for innovation for freeing up the key resources for building core competency as well This would lead for sales improvement, better profit, customer's satisfaction and better productivity of market share to measure the effectiveness of outsourcing strategy. (Femi Suraju, 2013).

Though many companies have used from outsourcing strategy for enhancing their competitiveness level, but still many others have not, has caused many others to ask which driving factor affects the decision to go for outsourcing strategy and how such outsourcing improves the organizational behavior. This includes reduced internal

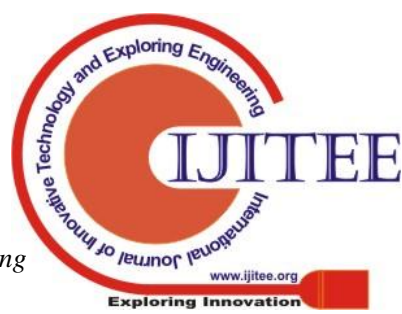


investment cost, for respond to confusion in business environment and developed offering service is the best preparation. (Chowdhury, 2012).

In fact, there is no doubt that outsourcing could be vital and strategic. However, the more important thing is better recognition of the strategic value the outsourcing could generate to any organization if managed correctly. The real risk is in losing the strategic intend of outsourcing in the day-to-day hustle and bustle of the organization's operations (BertrandQuélinFrançoisDuhamel, 2003).

It is further argued that in order to prevent losing sight of strategic intend, companies must create a robust and fast decision making process to manage the outsourcing relationship in such a manner that hard-wires the strategic operations (ChyanYang, 2000).

In the current dynamic environment, outsourcing has been one of the basic strategies, to remain competitive in the market, is being used by the companies. Outsourcing have some of their chain valued activities and responsibilities to third bodies. This is due to getting benefits in lower cost, better customer satisfaction and more importantly freeing the management to concentrate on the strategic issues function on specialized firms. (Musau, 2016).

The other benefits of outsourcing for the companies are maximizing resources, improvement of services and freeing up internal staff to focus on more strategic issues. Workforce productivity, leadership development as well as successful planning. Focusing of core competence and firm's desire could be the other reason of utilizing the for customers and tax advantages covered outsourcing is thought to be successful. (Agwu Edwin, 2015).

There is a strong relationship among outsourcing and its profitability. This claim is based on the $96 \%$ of respondents which outsourcing significantly contributes to the organization profitability. The organizations make the outsourcing decision based on variety of reasons; the cost reduction is the most important one. (Gyamfi, 2015).

The essential thing for successful outsourcing is risk management. The process whereby systematically organizing the risks attached to their activities with the aim of achieving sustainable benefits within portfolio of each activity. Within the supply chain, organizational profitability may reduce due to poor outsourcing. (Mwelu, 2016).

When working within the public sector or major organization by the demonstrate risk management process and capability you can increase your competiveness and profitability. All businesses are part of supply chain and each link perform the business, customers and suppliers.

The effective risk management avoids the need for time consuming, moreover it leads to stronger reputation, much more effective business outcomes and large-scale profitability. (Carcary, 2013).

Based on assessment of the losses in organization could determine the risk perspectives by the board of directors. The possibility of assessing risk typically involve an organization analytical process to identify the risks. Effective risk management allows the organization to understand better its risk profile. Managing risk help to been adopted by many organizations and institutions for outsourcing. When such financial economic expectations as the achievement of cash infusion, cost reduction lower price

improve their performance within the organization and effectively targeting the reduction of losses. Carefully selection of supplier collaboration initiatives and development as well. (Adusei-Poku, 2005).

In a large view, risk management would involve controlling risk, evaluating risk, analyzing risk, estimating risk and identifying risk. To understand the nature of the risk, as certain the impact and profitability of the potential risks on the supply chain. Risk Management can take place throughout the sourcing, stock piling, insurance and supplier to compare the estimate criteria, which the organization has already developed to have a corrective mechanism to improve the firm's profitability levels. (Kampala, 2014).

Quality assurance increases the outcome and confidence of risk management, allocation of resources to risk management, disaster recovery and business continuity plans, increased reputation and coordination with service and delivery patterns, hence customer attraction leading to more sales volumes and market share as a measure of profitability (Chapelle et. al, 2004.)

Outsourcing initiatives-whether for finance, IT, compliance, operations or other areas - often fail to meet expectations due to inadequate risk identification and early mitigation in the outsourcing project's lifecycle. Any firm can maximize the value of these initiatives by developing a risk management plan in the first phase to identify, evaluate and prioritize risks and mitigation strategies, and then implementing those strategies (Jae-Nam Lee, 2004).

One of the most significant issues that companies are facing as to start outsourcing journey is what skill, tools process and organization is needed to manage the ongoing relationship. Typically, early identifying and addressing of these risks in the outsourcing lifecycle leads to a more optimal outcome and greater benefits from outsourcing. (Bolina, 2014).

If the associated risks are not properly identified and managed, outsourcing cannot achieved the optimal benefits. For getting more gain compare to offset by significant losses, which not be only in financial terms but also in the areas of individual privacy and data security among others, should be careful considerations of various risk associated with outsourcing. (Agrawal, 2011).

\subsection{Research Gap}

The deference of the study not much more to any other study of this project; although, it can be differ in some issues, which make it distinguished such as:

Literature review of this project mainly focused on advantages, profitability and the benefit that the company earnings from its organizational performance, however, managing risk is the essential things for reduction of losses and obtaining profit and returning on shareholders. While this study suggest on customers perception regarding outsourcing and challenges that may face with outsourcing.

For many reason this study suggest for using outsourcing services in organization which derives companies and explain the factors that have direct impact on getting profit 
to the companies. Lastly, this project is the unique one because it explain the effects of outsourcing services through characteristics, organizational performance and challenges, which companies associated with. Based on the above arguments following hypotheses are developed.

Ha1: The use of Outsourcing strategy has impact on organization profitability.

Hb1: There is a significant correlation between outsourcing and organization profitability.

$\mathrm{Hb} 2$ : There is a significant correlation between outsourcing and organization profitability.

\section{RESEARCH METHODOLOGY}

\subsection{Methodology:}

For the purpose of research on the most discussed topic i.e. role of outsourcing in organization, a certain set of questionnaire were developed keeping in mind the impact of outsourcing process in organizations. A form with such questionnaire was floated through online form to people in different sector, to get their views and experience on outsourcing impact and profitability in performance of organization.

Sample size taken was 30 and the method followed was convenient sampling where the data was collected through online form, which was easily accessible.

\subsection{Research Technique:}

The quantitative research method by the help of structured questionnaire, which, include five point scale questions, has been used in this research project.

Moreover, for adding value in this study, different secondary data sources have been used to attained result, using quantitative research method is important because of the attaining of the good and efficient outcome is settled over objectives.

As, major part of objectives over the organization and associated outsourcing services, government initiative and challenges of outsourcing in a company, were attached with customers preference. So, by considering a quantitative research method the settle objective objectives can be attained efficiently and effectively.

\subsection{Limitation of the Study:}

The research of every project have some limitation area, and this research limited as follows:

Time was the main limitation of the study and lack of resources, lack of secondary data were the other limitation of this research.

Moreover, as we known that the government organization are mostly in the initial stage of providing outsourcing services. Hence, during the ongoing of classes, it was difficult to find time for preparing the data for analyzing the research and it was challengeable to gathering responses.

\section{DATA ANALYSIS \& RESULTS}

\subsection{Analysis and results:}

The research conducted for this project has led to findings that most of the organizations now prefer using of outsourcing for high profitability. The data collected from people across online form through social pages e.i Facebook, Watts up etc. that has shown a correlation between use of outsourcing in a company and the improved performance of such organization.

The rotated component matrix was used to find the similarity of the question after which we came across five main categories in which the data can be clubbed and identified. They are:

Component 1: Importance and usage of outsourcing

Component 2: The impact of outsourcing on organization profitability.

Component 3: Improvement of organizational performance by using of outsourcing.

Component 4: Effect on efficiency of corporation.

Component 5: Quality of risk management on outsourcing.

We can say from the above categorization that most of the employer and employee believe that outsourcing is important for better performance and profit in all organizations. However, research shows that the organization that using outsourcing is more successful and profitable than others, which are not using outsourcing. The improvement of organizational performance related to component of outsourcing as offshore outsourcing is more profitable than onshore outsourcing.

If the associated risks are not properly identified and managed, outsourcing cannot achieved the optimal benefits. For getting more gain compare to offset by significant losses, which not be only in financial terms but also in the areas of individual privacy and data security among others, should be careful considerations of various risk associated with outsourcing

\subsection{Result and Discussion of Questionnaire}

\subsubsection{Data analysis through SPSS}

Table- I: Reliability Statistics

\begin{tabular}{|r|r|l|}
\hline Cronbach's Alpha & $\begin{array}{l}\text { Cronbach's Alpha } \\
\text { Based on } \\
\text { Standardized Items }\end{array}$ & N of Items \\
\hline .771 & .365 & 12 \\
\hline
\end{tabular}

A. Cronbach's alpha is a measure of internal consistency, that is, how closely related a set of items are as a group. The higher the value of Cronbach's Alpha, the more consistent the data is.

B. The value of Cronbach's Alpha is 0.771 which it shows that the set of questions have relatively high consistency. 


\subsubsection{Factor Analysis}

Table- II: Communalities

\begin{tabular}{|l|l|l}
\hline & Initial & Extraction \\
\hline Role of outsourcing in business & 1.000 & .847 \\
Profitability of outsourcing & 1.000 & .768 \\
Geographical location of outsourcing & 1.000 & .816 \\
Importance of onshore & 1.000 & .683 \\
Organizational performance of & 1.000 & .706 \\
outsourcing & & \\
impact of outsourcing & 1.000 & .583 \\
Decision for outsourcing & 1.000 & .916 \\
Return in investment of outsourcing & 1.000 & .715 \\
Important components of outsourcing & 1.000 & .836 \\
Improvement in performance & 1.000 & .824 \\
Reasons for not out sourcing & 1.000 & .885 \\
impact of risk management & 1.000 & .617 \\
\hline
\end{tabular}

Extraction Method: Principal Component Analysis.

The table of communalities is estimated the variance in each variable accounted for, by the components. The communality value should be greater than 0.5 to be considered for further analysis. The communalities in this table are all high (more than 0.5), which indicates that the extracted components represent the variables well. If any communality is very low, then then variables are to be removed from further steps of factor analysis.

Table- III: KMO and Bartlett's Test

\begin{tabular}{|l|l|}
\hline $\begin{array}{l}\text { Kaiser-Meyer-Olkin Measure of Sampling } \\
\text { Adequacy. }\end{array}$ & 544 \\
\hline & \\
Bartlett's Test of Sphericity Approx. Chi-Square & 113.983 \\
df & 66 \\
Sig. & 000 \\
\hline
\end{tabular}

The Kaiser-Meyer-Olkin Measure of Sampling Adequacy is a statistic, which determines if the responses given with the sample are adequate, or not. The value of this statistic lies from 0 to 1 . High values generally indicate that a factor analysis may be useful with your data. Here, the value of Kaiser-Meyer-Olkin Measure is 0.544, which shows that the sampling is adequate.

Bartlett's test of sphericity is the other indication of the strength of relationships among the given variables. It tests whether your variables are related or not and therefore unsuitable for structure detection. Small values (less than 0.05) of the significant level indicate that a factor analysis may be useful with your data. The significance value of Barlett's test of Sphericity is 0.000 , which also shows that factor analysis will be useful to the data. The significance value is less than 0.05 , which shows the null hypothesis is rejected, alternate hypothesis is rejected, and alternate hypothesis is accepted.

Thus, the use of outsourcing strategy has impact on organizational profitability and improvement of organization performance. In addition, there is a significant correlation between outsourcing strategy and organization profitability.

Eigen value is the amount of variance that each component or factor explains. If the Eigen value is more than 1 , then considerable amount of variable is explained. Here, the Eigenvalue table shows five different components under Extraction Sums of Squared Loadings, which shows that all the variables fall under these three components. The minimum value of the cumulative percentage of Initial Eigen values of these three components should be minimum $60 \%$.

Table- IV: Total Variance Explained

\begin{tabular}{|c|c|c|c|c|c|c|c|c|}
\hline \multirow[b]{2}{*}{$\begin{array}{l}\text { Compo } \\
\text { nent }\end{array}$} & \multicolumn{2}{|c|}{ Initial Eigen values } & \multicolumn{3}{|c|}{ Extraction Sums of Squared Loadings } & \multicolumn{3}{|c|}{ Rotation Sums of Squared Loadings } \\
\hline & \% of Variance & Cumulative \% & Total & \% of Variance & Cumulative \% & Total & $\begin{array}{cc}\% & 0 \\
\text { Variance }\end{array}$ & Cumulative \% \\
\hline 1 & 24.059 & 24.059 & 2.887 & 24.059 & 24.059 & 2.465 & 20.542 & 20.542 \\
\hline 2 & 18.635 & 42.603 & 2.236 & 18.635 & 42.693 & 2.138 & 17.814 & 38.356 \\
\hline 3 & 14.488 & 57.181 & 1.739 & 14.488 & 57.181 & 1.696 & 14.136 & 52.492 \\
\hline 4 & 10.041 & 67.222 & 1.205 & 10.041 & 67.222 & 1.66 & 13.66 & 65.959 \\
\hline 5 & 9.404 & 76.626 & 1.128 & 9.404 & 76.626 & 1.280 & 10.668 & 76.626 \\
\hline 6 & 7.442 & 84.068 & & & & & & \\
\hline 7 & 4.098 & 88.166 & & & & & & \\
\hline 8 & 3.572 & 91.738 & & & & & & \\
\hline 9 & 2.950 & 94.688 & & & & & & \\
\hline 10 & 2.306 & 96.993 & & & & & & \\
\hline 11 & 1.731 & 98.724 & & & & & & \\
\hline 12 & 1.276 & 100.000 & & & & & & \\
\hline
\end{tabular}

Extraction Method: Principal Component Analysis.

Table- V: Scree plot is a graph of the eigenvalues against all the factors. The minimum Eigenvalue is 1.Rotated Component Matrixa

\begin{tabular}{|c|c|c|c|c|c|}
\hline & \multicolumn{5}{|c|}{ Component } \\
\hline & 1 & 2 & 3 & 4 & 5 \\
\hline Role of outsourcing in business & -.166 & -.702 & .096 & .471 & .308 \\
\hline Profitability of outsourcing & .098 & .041 & .833 & .029 & .247 \\
\hline Geographical location of outsourcing & -.048 & -.055 & -.717 & .505 & .206 \\
\hline Importance of onshore & .072 & .729 & .246 & -165 & .243 \\
\hline Organizational performance of outsourcing & .835 & -.020 & -.026 & .069 & .056 \\
\hline impact of outsourcing & .733 & .055 & .197 & -.019 & .065 \\
\hline Decision for outsourcing & .110 & .054 & .082 & -.152 & .933 \\
\hline Return in investment of outsourcing & .828 & .147 & .081 & .034 & .003 \\
\hline Important components of outsourcing & 317 & .660 & -.474 & .229 & .149 \\
\hline Improvement in performance & .470 & .637 & -.036 & .371 & -.240 \\
\hline Reasons for not out sourcing & -.050 & .018 & .150 & .894 & .245 \\
\hline impact of risk management & -.406 & .488 & .343 & .304 & .068 \\
\hline
\end{tabular}

The rotated component matrix reduces the number of factors on the variables, which have high loadings. Factor loading is a simple correlation of each variable with particular component. The value of each variable under a component should be greater than 0.5 to fall under that specific component.

Component 1: Importance and usage of outsourcing in a business to company.

Component 2: The impact of outsourcing on organization profitability.

Component 3: Improvement of organizational performance by using of outsourcing.

Component 4: The components effecting on reliable efficiency of corporation.

Component 5: Quality of risk management on outsourcing. 


\subsubsection{Scree Plot}

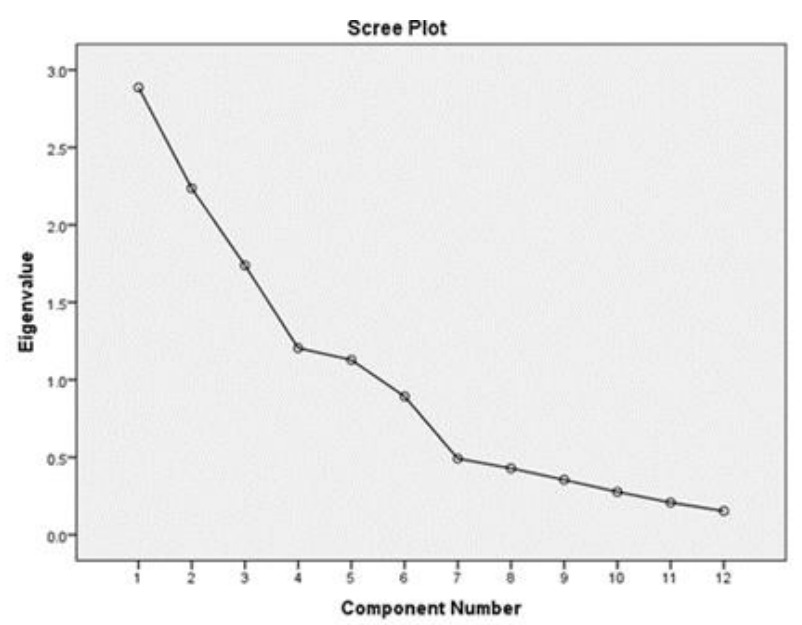

Component Transformation Matrix

\begin{tabular}{|l|l|l|l|l|l|}
\hline \multicolumn{1}{|c|}{ Componen } & 1 & 2 & 3 & 4 & 5 \\
\hline 1 & & & & & \\
2 & .799 & .567 & -.156 & .125 & -.018 \\
3 & .050 & .263 & .686 & -.615 & .282 \\
4 & .589 & -.776 & .043 & -.169 & .144 \\
5 & -.042 & .007 & .167 & .558 & .812 \\
\hline & -.104 & .086 & -.689 & -.516 & .490 \\
\hline
\end{tabular}

Extraction Method: Principal Component Analysis.

Rotation Method: Varimax with Kaiser Normalization.

The component Transformation Matrix is used to check whether the components are correlated with each other. However, here none of components has the value of greater than 0.5 , which shows the components are not correlated.

\section{RECOMMENDATION}

This research as every research had some shortages and applies connection with the outsourcing services, which companies are providing in organization performance. Hence, with compliance with the desire, necessities and requirements of organizations and current market, should find the best solutions and recommendation for providing a successful and effective outsourcing services.

1- For encouraging the organization for the utility of outsourcing, the companies should develop, activate and innovate new technologies.

2- By providing security, variety, most convenient and contemporary outsourcing management companies differentiate themselves from competitors. Moreover, the companies which provide convenient and variety outsourcing services, can gain and earning huge profitability

3- Taking appropriate decisions and managing effectively causing to assure successful outsourcing services in organizational performance.

4- The most important thing that a company should focus on is the generating value for organizations, which company can earn with outsourcing.

5- Organization's policies and procedures should be transparent and any updating or revision in the same shall be then cascade to the companies.
6- Outsourcing is the future of companies, which helps in improving managing the organization performance with acceptable returning. The contents of the journal are peer-reviewed and archival. The journal publishes scholarly articles of archival value as well as tutorial expositions and critical reviews of classical subjects and topics of current interest.

\section{CONCLUSION}

\subsection{Conclusion:}

The overall research has led us to know the influence of outsourcing in every organization performance. Organizations are approaching to profit by using outsourcing as it has becomes more convenient. Also from the research, it has been clear that providing high work performance within organization. Most of the organizations believe that outsourcing can provide high services with customer satisfaction. The attitude of employers while company has been outsourced has positive impact on organizational profitability and due to the revolution; it is increasing day by day. All those companies in all countries around the world, which are outsourced, is more profitable.

\section{ACKNOWLEDGMENT}

With the grace and blessing of most merciful, Almighty Allah and hard work, I have completed this research project. In Addition, support of my respectable professors on this research project was great. Especially, I would like to express my gratitude to Dr. Shantanu Prasad for his frequent support, leadership and guidance as the project supervisor of my research work, as without his support and guidance this work would not have been possible.

I am thankful to my other respectable professors, academic advisory board and fellows at Symbiosis International (Deemed University), for their valuable support.

At the Symbiosis Centre for Management and Human Resource (SCMHRD), I am grateful to my classmates and all others who supported me.

Lastly, my profound gratitude goes to my family who always support me in life during struggle and help me in achieving success. The motivation and prayers of my parents are so valuable.

\section{REFERENCES}

1. Rick L, Click Thomas N Duenign, (2005). Business Process Outsourcing, Kobokan, New Jersey.

2. Dayasindhu, N. (2004). Information technology enabled process outsourcing and reengineering. Case study of a mortgage bank. New York: Proceedings of the Americas Conference on Information Systems.

3. Halvey, J. K., \& Melby, B. M. (1996). Information technology outsourcing transactions. Processes,strategies, and contracts. New York: Wiley.

4. Ang, S., \& Straub, D. (1998). Production and transaction economies and IS outsourcing. A study of the U.S. Banking Industry. 
5. Deepa Mani Anitesh Barua Andrew B Whinsto.()Successfully Governing Business Process outsourcing relationships.University of Texas at Austi

6. Heiko Gewald,Kim Wüllenweber,Tim Weitzel.().The influence of perceived risks on banking managers intention to outsource business processes - a study of the german banking and finance industry.Institute of Information Systems Johann Wolfgang Goethe University Frankfurt am Main

7. Nicholson Brain, Aman Aini. (2008). Offshore Accounting Outsourcing. The case of India. England.

8. Benoit A Aubert,Michel Patry,Suzzani Rivard .(). Assessing the risk of IT outsourcing.Ecole des, hautes Etudes Commercials 3000 Chrmin de la Cote- SteCatherine Montreal, Quebec, Canda H3T 2A7

9. Ravi Aron Eric K. Clemons Sashi Reddi.(2005).Just Right Outsourcing: Understanding and Managing Risk.The Wharton School, University of Pennsylvani

10. Bakos, Y. and Brynjolfsson, E. "From Vendors to Partners: Information Technology and Incomplete Contracts in BuyerSupplier Relationships", Journal of Organizational Computing, Volume 3, Number 3, December 1993.

11. Brynjolfsson, E., Malone, T., Gurbaxani, V. and Kambil A. (1994). "Does Information Technology Lead to Smaller Firms", Management Science, vol. 40, Issue 12, pp. $1628-1644$.

12. Clemons, E., Reddi, S., and Row, S. (1993). "The Impact of Information Technology on the Organization of Economic Activity: The 'Move to the Middle' Hypothesis", Journal of Management Information Systems, Vol. 10 (2), pp. 9-35.

13. Coase, R. (1937). "The Nature of the Firm", Economica, vol. 4, pp. 386-405.

14. Hitt, L. (1999). "Information Technology and Firm Boundaries: Evidence from Panel Data", Information Systems Research, vol.10, pp. 134-149.

15. Gulzhanat Tayauova.(2012).Advantages and disadvantages of outsourcing: analysis of outsourcing practices of Kazakhstan banks.Kazakh-British Technical University, Almaty, 050000, Kazakhstan

16. R. Chandrasekaran,Ahmed Tayeh,Vaishali Nagoore.(2007).Understanding Information System Outsourcing Failure: Lessons from a Case Stud.University of Illinois at Chicago

17. (https://www.outsource2india.com.19/09/2018. 7:12 $\mathrm{PM})$.

18. Adusei-Poku, K. (2005). Operational Risk management . University of G"ottingen.

19. Agrawal, S. (2011). Challenges of ITES Companies in India. International Journal of Humanities and Social Science

20. Agwu Edwin, O. (2015). Strategic Management of the Benefits and Challenges of HR. Journal of Business Studies Quarterly.

21. BertrandQuélinFrançoisDuhamel. (2003). Bringing Together Strategic Outsourcing and Corporate Strategy: Outsourcing Motives and Risks. European Management Journal.

22. Bolina, A. (2014). Managing Outsourcing Risks at the Early Stages. CFO JOURNAL.

23. Carcary, M. (2013). IT Risk Management: A Capability Maturity Model. The Electronic Journal Information Systems Evaluation, 1-5.

24. Chowdhury, M. S. ( 2012). Impact of Outsourcing on Company Performance:. Institute of Governance Studies, 1-4.

25. ChyanYang, J.-B. (2000). A decision model for IS outsourcing. International Journal of Information Management.

26. Femi Suraju, A. B. (2013). Outsourcing Services as a Strategic Tool for Organizational Performance: An Journal of Management Policies and Practices .

27. Gyamfi, L. A. (2015). Evaluating the impact of outsourcing on. World Wi de Jou rnal of Mu lti disci plin a ry Researc h and Dev elop men t, 26-29.

28. Henderson, J. C., \& Venkatraman, H. (1999). Strategic alignment: Leveraging information technology for transforming organizations. IBM Systems .

29. Jae-Nam Lee, S. M.-M. (2004). IT Outsourcing Strategies: Universalistic, Contingency, and Configurational Explanations of Success. INFORMS Journal on Optimization.

30. Kampala. (2014). Risk management and profitability of manufacturing firms in. Department of Entrepreneurship of Makerere University Business School, P. O. Box $1337,49-52$.

31. Musau, C. N. (2016). The Impact of Strategic Outsourcing on Organizational Performance: A Case Study of Bidco Africa Limited. United States International University - Africa.

32. Mwelu, N. (2016). Risk management and profitability of manufacturing firms in Uganda. University of Newcastle, $49-51$.

\section{AUTHORS PROFILE}

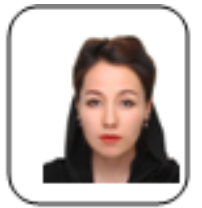

Jamila Niazi is a student of MBA, Sem-III (2018-2020) at SCMHRD.

Author-2 Photo
Dr. Shantanu Prasad is Assistant Professor of Marketing at SCMHRD. He also heads MBA (Executive) program of the school. $\mathrm{He}$ has published many research papers in peer reviewed ABDC/ABS ranked journals. His teaching interests are: Marketing Analytics, Marketing Research

Business Research Method and Marketing Management. 